\title{
Resenha do LIVRO Jogada POLÍTICA NO ESPORTE: O CONFRONTO ENTRE OS JOGOS POLÍTICOS E OS ESPORTES OLÍMPICOS
}

\section{Quéfren Weld Cardozo NOGUEIRA*}

O livro do jornalista Fábio Piperno, Jogada política no esporte: o confronto entre os jogos políticos e os esportes olímpicos, publicado pelo SESI-SP em 2016, aborda aquilo que o autor denomina de jogadas políticas ou lances diplomáticos no esporte. Para trabalhar tal assunto, ele elege acontecimentos nos quais ocorreram embates em torno da participação de atletas em eventos esportivos.

O livro é dividido em 17 pequenos capítulos, sendo que os 5 últimos tematizam o boicote aos Jogos Olímpicos. As análises feitas compartilham o entendimento de que o esporte é perpassado por intervenções políticas que atendem determinados interesses ideológicos, maculando assim uma suposta neutralidade do fenômeno esportivo $^{1}$. As histórias se distanciam de acontecimentos de maior divulgação midiática e elegem acontecimentos pouco conhecidos do grande público. Segundo o autor, "os fatos que apresentamos ao leitor não são únicos e talvez nem os mais emblemáticos do histórico dessa relação incestuosa entre política e esporte. Mas todos os eventos e personagens destacados se mostram emblemáticos nos momentos aqui narrados" (PIPERNO, p. 13).

Apesar de ser uma obra para o público brasileiro, o livro não trabalha com a relação entre política e esporte no Brasil. Tal questão é levantada pelo prefaciador, Caio Luiz de Carvalho, Ministro de Esportes e Turismo, entre 2001 e 2003. Há aqui uma crítica à gestão ministerial do esporte, que fez do futebol a agenda única do Ministério, após a escolha do Brasil como sede da Copa do Mundo da FIFA em 2014. A culpa para pouca quantidade de medalhas olímpicas para o Brasil

\footnotetext{
UFS - Universidade Federal de Sergipe. Centro de Ciências Biológicas e da Saúde. 49100000 - São Cristóvão, SE - Brasil. ufsquefren@gmail.com.

1 Cf. Tubino (1992), particularmente quando este trata da evolução conceitual do esporte e do seu uso político ideológico.
} 
é colocada nas três esferas do governo, que ainda não assumiram plenamente o esporte como uma questão de Estado. O Ministério do Esporte se tornou mais um Ministério do Futebol, enquanto que um trabalho com o esporte para abranger diversas modalidades e atender toda a população deveria vincular-se ao Ministério e às Secretarias Estaduais de Educação.

Jogada política no esporte é uma obra jornalística que busca provocar emoções com uma quantidade excessiva de adjetivos presentes no decorrer do texto. A leitura me fez lembrar de Recordações do escrivão Isaías Caminha de Lima Barreto, o qual, ao discorrer acerca das matérias jornalísticas sobre as provas de turfe no Rio de Janeiro no início do século XX, coloca: "Não há nada mais enfadonho que uma crônica de corridas. Quem lê, lê todas. Excetuando os dados de momento, são escritas com os mesmos verbos, os mesmos adjetivos, os mesmos advérbios" (BARRETO, s/d, p. 131). De qualquer forma, Jogada política no esporte é uma obra que nos ressalta os significados sociais da competição esportiva, cujos resultados avançam sobre as linhas de uma quadra ou campo e abrangem uma ampla conotação política e social. Nesse sentido,

Competir não é brincar, recrear, distrair o tempo, entreter-se; jogar pode significar a simulação de uma atividade competitiva ou um arremedo de competição. $\mathrm{O}$ desafio, quando envolve perigo ou risco, não é brinquedo ou jogo. No desafio que arma a competição há é luta e esta se impõe o emprego de atributos culturais. [...] A competição é o jogo levado a sério, e, por isto, não se esgota na epiderme lúdica do homem que se distrai ou se diverte (LYRA FILHO, 1973, p. 17).

O primeiro capítulo do livro, "Os três segundos mais longos do esporte", destaca a final do Torneio Olímpico de Basquetebol nos Jogos de Munique 1972, quando a União Soviética derrotou os Estados Unidos após polêmicas sobre a cronometragem final da partida e a intervenção de dirigentes no encerramento do jogo. O autor sugere uma conexão entre este acontecimento - juntamente com uma nova derrota americana nos Jogos de Seul 1988 - e o posterior aceite de atletas profissionais como integrantes de uma equipe olímpica de basquetebol.

O segundo capítulo, "O homem branco da foto", discorre sobre os atletas norte-americanos Tommie Smith e John Carlos, que nos Jogos do México em 1968, ergueram o punho cerrado, envolto em uma luva preta, como forma de protestar contra o racismo nos Estados Unidos - a imagem de Tommie Smith no pódio, neste momento, é capa do livro de Piperno. O medalhista de prata nessa competição dos 200 metros rasos no atletismo, o australiano Peter Norman, mesmo não erguendo o braço, prendeu em seu peito um broche representativo da Olympic Project for Human Rights (OPHR), uma organização de atletas que protestavam contra o 


\section{Resenha do livro Jogada politica no esporte: o confronto entre os jogos politicos e os esportes olimpicos}

racismo nos Estados Unidos. O relato do livro aborda primordialmente a perseguição aos atletas, desde a expulsão destes da vila olímpica até o ostracismo do australiano quando do seu retorno às competições de atletismo.

O terceiro capítulo, "Sangue nas águas", versa sobre a rivalidade no polo aquático entre a seleção da Hungria e a da União Soviética, em um momento quando os húngaros resistiam contra a invasão soviética em seu país. O jogo da semifinal entre estas equipes nos Jogos de Melbourne 1956 é apresentado como o desafio de um pequeno país contra o potencial bélico dos soviéticos.

A atuação do mesa-tenista inglês Ivor Montagu, simpatizante do regime comunista chinês sob a direção de Mao Tsé-Tung, é retratada no quarto capítulo "O espião que amava o tênis". Montagu é apontado como o principal diplomata na aproximação dos Estados Unidos com a China, intermediando um evento que ficou conhecido como Diplomacia Ping Pong. Esse também é o título do quinto capítulo, quando a amizade entre dois atletas - o chinês Zhuang Zedong e o norteamericano Glenn Cowan - produziu imagens que chamaram a atenção do líder chinês e incentivaram um convite para a delegação americana de tênis-de-mesa visitar a China.

Chegando ao sexto capítulo, "A libélula loira da Primavera de Praga", Piperno escolhe como protagonista a ginasta da Tchecoslováquia Vera Caslavska, que se tornou refugiada após demonstrar simpatia por movimentos liberalizantes do regime comunista. Na decisão do solo, Caslavska teve que dividir a medalha de ouro com uma atleta soviética, após uma intervenção nas notas da fase preliminar. A divisão de um mesmo espaço no pódio por duas atletas de países rivais representou para Piperno a invasão de uma superpotência a um país menor. Anos mais tarde, Caslavska se tornou protagonista na negociação por Petróleo entre a Tchecoslováquia e o México, quando no intermédio das negociações o presidente mexicano José López Portillo solicitou a permissão para que a atleta orientasse a seleção de ginástica local.

O capítulo sétimo, "Conto de fadas na Guerra Fria", retrata o relacionamento entre o americano Harold Conolly, do lançamento de martelo, e Olga Fikotová, atleta tcheca do lançamento de disco. Após se conhecerem na Vila Olímpica, os dois tiveram problemas para manter um relacionamento. Em um primeiro momento, a permissão para se casarem ocorreu sob a condição de que Fikotová continuasse a defender a Tchecoslováquia de origem, fato que não ocorreu, já que o Comitê Olímpico tcheco comunicou posteriormente que a atleta estava dispensada de representar aquele país.

"Campeão, rebelde e best-seller", título do oitavo capítulo, foca no atleta de levantamento de peso Yuri Vlasov, da União Soviética, e sua amizade com Jim Bradford, dos Estados Unidos, medalhistas de ouro e prata nos Jogos de Roma 
1960, respectivamente. Bradford fora convidado por Vlasov para visitar a União Soviética, o que permitiu ao norte-americano entrar em contato com os benefícios que um grande atleta soviético podia receber. Nesse entremeio, Piperno adentra na questão da Doutrina Hallstein, que afirma que a Alemanha é apenas uma e propunha o rompimento com todos os países - menos a União Soviética - que reconhecessem a autonomia da Alemanha Oriental. Tal doutrina foi utilizada em 1961 no Campeonato Mundial de Hóquei para justificar a desistência da Alemanha Ocidental em disputar o quinto lugar com a Alemanha Oriental. Além disso, outros eventos foram atingidos pelos mesmos motivos, como o Mundial de Esqui, realizado em Chamonix, França, que vetou a participação de atletas do leste europeu.

O nono capítulo, denominado "Um coreano feito japonês", conta a história de Sohn Kee-chung, um coreano inscrito nos Jogos de Berlim 1936 com o nome japonês de Kitei Son, em um período em que a Coréia estava anexada ao Japão. No pódio havia outro atleta coreano, Nam Sung-yong, que acabou se tornando Shoryu Nam. A história desses dois atletas é pano de fundo para discutir a relação dos japoneses com países orientais, especificamente a China e a Coréia. Adiante, a medalha de ouro conquistada no heptatlo por Ghada Shouaa, da Síria, é tema do décimo capítulo, “A campeã de ouro da família Assad”. A conquista de uma mulher síria e cristã é apontada como um símbolo de tolerância em um país de maioria muçulmana.

Em sequência, para tratar da relação de países africanos com o Comitê Olímpico Internacional (COI), Piperno discorre sobre o Burundi, um pequeno país que pela primeira vez participava de uma edição dos Jogos Olímpicos em Atlanta, em 1996. O autor elege no décimo primeiro capítulo, intitulado "Campeão contra a guerra fratricida", o trabalho de Dieudonné Kwizera, com seu incentivo para que jovens atletas do Burundi participassem dos Jogos Olímpicos. Dentre estes destacou-se Venuste Niyongabo, cujas condições precárias de treinamento o levaram para treinar na Itália, enquanto em sua terra de origem ocorria um conflito interno. Niyongabo acabou se tornando campeão olímpico pelo Burundi na prova de 1.500 metros no atletismo.

"O regime que derrotou o time de Puskás", o décimo segundo capítulo, faz um relato sobre os acontecimentos em torno do amistoso entre o Flamengo do Rio de Janeiro e o time representante do exército húngaro, o Honved, que contava com o conceituado jogador Ferenc Puskás Biró. O time do Honved fazia uma excursão pela Europa no período em que Budapeste estava tomada pelo exército soviético, e com vários atletas pedindo refúgio em países estrangeiros. $\mathrm{O}$ aceite do convite para amistosos no Brasil selou o rompimento de vários atletas com o regime comunista, pois havia então uma pressão para que os jogadores voltassem para a Hungria.

Os cinco últimos capítulos são dedicados aos boicotes olímpicos. O primeiro deles, "Lista Tríplice do boicote a Melbourne", examina os conflitos em torno dos 


\section{Resenha do livro Jogada politica no esporte: o confronto entre os jogos politicos e os esportes olimpicos}

Jogos de Melbourne na Austrália em 1956, e as confluências no boicote do Egito, Israel e Líbano, por causa de um conflito causado pelo fechamento pelo Egito do Estreito de Tiran, que liga Israel ao Mar Vermelho. Ainda, por causa da invasão soviética à Budapeste, Espanha, Holanda e Suiça boicotaram os Jogos de 1956. Este capítulo discorre também acerca dos conflitos entre a República Popular da China e o COI, que aceitou a participação de Taiwan nos Jogos Olímpicos, o que fez com que a China se retirasse do evento e só retornasse em 1984, na edição de Los Angeles.

O capítulo seguinte, "O clássico do rúgbi que ofendeu a África", ocupase do incidente provocado pelo time de rúgbi neozelandês quando da disputa de um amistoso contra a seleção da África do Sul, então sob o regime do apartheid nessa época, as equipes sul-africanas estavam banidas de eventos internacionais. Houve então um pedido por parte de países africanos para o COI excluir a Nova Zelândia dos Jogos de Montreal em 1976. Tendo o pedido negado, 28 delegações principalmente de países africanos deixaram de participar do evento.

O capítulo intitulado "Por quem foram as lágrimas de Misha?" faz alusão ao mascote que na cerimônia de encerramento dos Jogos de Moscou em 1980 derramou uma lágrima, se tornando uma das imagens mais divulgadas de um evento olímpico. Na visão de Piperno, tal lágrima foi fruto do esvaziamento dos Jogos causado pelo boicote de países liderados pelos Estados Unidos, em protesto contra a invasão do Afeganistão pela União Soviética. Em resposta, o capítulo intitulado "Retaliação soviética esvazia Los Angeles" trata do boicote soviético nos Jogos seguintes em Los Angeles, 1984, quando diversos países alegaram motivos como a excessiva comercialização do evento, a ausência de segurança e a propagada antissoviética para deixarem de participar daqueles Jogos.

O último capítulo lida com "Os boicotes frustrados", ou seja, os planos de boicotes que não foram levados à frente: a delegação irlandesa cogitou não participar dos Jogos de Londres de 1908; o Império Austro-húngaro ameaçou boicotar os Jogos, caso o COI permitisse a participação da Hungria, Boêmia e da Tchecoslováquia; a tentativa de transferência dos Jogos de Berlim 1936, dada a denúncia das atividades antissemitas e racistas da Alemanha nazista.

De modo geral, em Jogada política no esporte, os conceitos utilizados pelo autor não são esclarecidos e não há um referencial teórico para conduzir as reflexões. Há uma vasta bibliografia consultada para a confecção do livro, o que exigiu do autor a capacidade de englobar uma grande quantidade de informações em um número reduzido de páginas. Porém, trata-se uma obra que deve agradar aos que possuem no esporte um tema de interesse e de investigação. 


\section{REFERÊNCIAS}

BARRETO, Lima. Recordações do escrivão Isaías Caminha. Rio de Janeiro: Ediouro, s/d. LYRA FILHO, João. Introdução à sociologia dos desportos. Rio de Janeiro: Bloch Editores; 1973. (Biblioteca do Exército, v. 113).

PIPERNO, Fábio. Jogada política no esporte: o confronto entre os jogos políticos e os esportes olímpicos. São Paulo: SESI-SP Editora, 2016.

TUBINO, Manoel J. Gomes. Esporte e cultura física. São Paulo: IBRASA, 1992.

Recebido em 16/08/2017.

Aprovado em 17/11/2017. 